\title{
CONTRIBUTOS PARA UMA ANÁLISE SEMÂNTICO- PRAGMÁTICA DAS CAUSAIS DE ENUNCIAÇÃO NO PORTUGUÊS EUROPEU CONTEMPORÂNEO
}

\author{
Ana Cristina Macário LOPES*
}

- RESUMO: O objetivo deste trabalho é caracterizar as orações causais de enunciação num quadro teórico que postula a existência, no discurso, de distintos domínios da significação domínio do conteúdo, domínio epistémico e domínio ilocutório-, na convicção de que uma análise semântica destas construções poderá contribuir para iluminar o seu comportamento sintático peculiar, que tanta controvérsia tem gerado. Defende-se, neste estudo, que as orações causais de enunciação expressam a relação discursiva de Justificação, que envolve sempre a articulação de dois atos ilocutórios, um deles com o estatuto de ato principal, o outro com o estatuto de ato subordinado. Num primeiro momento, analisa-se a articulação entre causais de enunciação e asserções e argumenta-se a favor da inseparabilidade entre os domínios epistémico e ilocutório neste tipo de construções, contrariamente ao que defende Sweetser (1999). Num segundo momento, analisa-se a articulação entre causais de enunciação e outras classes de atos ilocutórios, nomeadamente atos diretivos, compromissivos e expressivos.

- PALAVRAS-CHAVE: Causais de enunciação. Subordinadas periféricas. Ato ilocutório. Relação discursiva.

\section{Introdução}

Muitos linguistas admitem hoje que, no âmbito das orações subordinadas adverbiais, é possível estabelecer uma distinção entre adverbiais de predicado (ou integradas) e adverbiais de frase (ou periféricas). Esta distinção está contemplada em gramáticas de referência de várias línguas (QUIRK et al., 1985; RENZI; SALVI; CARDINALETTI, et al., 2001; BOSQUE; DEMONTE, 1999) e recobre basicamente a distinção entre advérbios de predicado e advérbios de frase.

Trata-se de uma distinção que se baseia fundamentalmente em critérios de natureza sintática, nomeadamente a posição prototípica que ocupam na frase matriz, bem como o comportamento distinto relativamente a um conjunto de testes que envolvem a focalização por clivagem, o escopo da negação de foco, a resposta a interrogativas $\mathrm{Ou}$-, a possibilidade de ocorrerem no escopo de operadores de

* UC - Universidade de Coimbra. Faculdade de Letras - Centro de Estudos de Linguística Geral e Aplicada. Coimbra - Portugal. 304-530 - acmlopes@fl.uc.pt 
foco de natureza adverbial como só ou até, a possibilidade de ocorrência em interrogativas e negativas alternativas. As subordinadas adverbiais de predicado podem ocorrer no final de frase sem serem precedidas por pausa entoacional e respondem positivamente aos testes acima mencionados. Já as subordinadas adverbiais de frase só ocorrem em posição final quando precedidas de pausa entoacional e respondem negativamente aos testes em apreço. ${ }^{1}$

É ainda relativamente consensual que as adverbiais de frase admitem subdivisões, tendo em conta (i) o seu estatuto mais ou menos periférico relativamente à frase matriz e (ii) o domínio da significação em que opera a relação discursiva marcada através do conector.

Já em Quirk et al. (1985) se propõe uma distinção entre 'content disjuncts' e 'style disjuncts', sendo estes últimos mais periféricos e funcionando como modificadores da enunciação. Em Kortmann (1996), é igualmente aceite como adquirido que as adverbiais mais periféricas funcionam como 'speech act modifiers'.

Este trabalho propõe-se contribuir para uma caracterização semânticopragmática das causais de enunciação no Português europeu contemporâneo. Assume-se, na esteira de autores como Halliday (1973), Dijk (1977), Lyons (1977), Sweetser (1999), Hengeveld (1993), Sanders et al. (1992), entre outros, que a significação expressa através da linguagem verbal não se reduz ao domínio semântico-referencial, antes inclui também o domínio pragmático-funcional. Isto porque a linguagem verbal não é apenas um sistema simbólico de representação do mundo, mas é também um instrumento através do qual desenvolvemos raciocínios e interagimos socialmente. Assim, tentar-se-á demonstrar, ao longo deste trabalho, que as construções em apreço só podem ser cabalmente descritas e explicadas tendo em conta o domínio pragmático-funcional da significação. Por outro lado, assume-se que uma caracterização semântico-pragmática das causais de enunciação pode contribuir para iluminar o seu comportamento sintático.

Os dados utilizados neste trabalho envolvem exemplos construídos e dados empíricos extraídos do CETEMPúblico e do Corpus do Português (2006), de Davies e Ferreira (doravante CdP).

A estrutura do artigo é a seguinte: num primeiro momento, discute-se brevemente a distinção entre causais de enunciado e causais de enunciação; seguidamente, propõe-se uma caracterização semântico-pragmática das causais de enunciação, quando articuladas com uma asserção; por fim, analisam-se as possíveis articulações entre causais de enunciação e outras classes de

Confira Lobo (2003), um trabalho de referência para o Português sobre a sintaxe das orações subordinadas adverbiais, que ilumina de forma inovadora a interface entre sintaxe e discurso. 
atos ilocutórios. Nas considerações finais, evidenciam-se as conclusões mais relevantes da pesquisa.

\section{Causais de enunciado vs. causais de enunciação}

Como é sabido, não há convergência absoluta, na comunidade linguística, relativamente ao estatuto subordinado ou coordenado das causais de enunciação (chamadas explicativas, na tradição gramatical). Lobo (2003) defende que as causais introduzidas pelos conectores pois, que e porque com valor explicativo se aproximam das construções de coordenação. Lopes (2004) argumenta a favor da inclusão das causais explicativas introduzidas por pois nas construções paratáticas, considerando hipotácticas periféricas as que são introduzidas por visto que, uma vez que, dado que, posto que e como. Matos (2004) defende que as orações explicativas apresentam propriedades que as aproximam da subordinação frásica, embora reconheça que exibem um grau fraco de coesão relativamente à frase com que se articulam. Embora o nosso objetivo não seja desenvolver uma análise sintática das construções em apreço, a análise semânticopragmática que a seguir se proporá poderá iluminar o seu comportamento sintático, gerador de forte controvérsia.

Do ponto de vista semântico, as distinções que têm parametrizado as tipologias das construções causais, independentemente da flutuação terminológica existente, podem ser equacionadas, sinteticamente, do seguinte modo:

(i) por um lado, há construções causais que operam no plano semântico (as chamadas causais de conteúdo, causais de re ou causais de enunciado), explicitando um nexo de causa/consequência entre situações do mundo descritas ao nível dos conteúdos proposicionais articulados através do conector, e dando origem a um enunciado que funciona como uma unidade entoacional e corresponde a uma só asserção (o locutor assere a relação causal entre p e q), ${ }^{2}$ como se ilustra em (1):

(1) As ruas estão molhadas porque choveu.

(ii) por outro lado, há construções causais que operam no plano pragmático (as chamadas causais de enunciação, causais de dicto ou causais explicativas), nas quais o nexo causal não é estabelecido com a predicação expressa na tradicionalmente chamada oração principal, mas sim com a enunciação dessa mesma predicação, havendo sempre uma pausa marcada entre a primeira e a

2 De notar que, como de forma pioneira sublinhou Lopes (1971), a causa não é necessariamente uma condição suficiente verificada na realidade. Pode ser apenas uma razão, um motivo que o falante convoca para explicar uma determinada situação. Confira também Neves (1998). 
segunda oração. Ou seja, neste último sub-conjunto, o locutor explicita a razão, o motivo que o leva a dizer algo, como se ilustra em (2): ${ }^{3}$

(2) O Rui está em casa, porque as luzes estão acesas.

Já em Quirk et al. (1985) se encontra esta bipartição básica entre a expressão de uma razão direta (causais de enunciado ou de re) e a verbalização de uma razão indireta (causais de dicto). Estas últimas integrariam o que os autores designam de 'style disjuncts', relacionados com a enunciação e revelando um escasso grau de integração sintática na frase matriz. Também em Kortmann (1996) se assume como dado adquirido que há orações causais fortemente periféricas, que são rotuladas de 'speech act modifiers' ou 'speech act adverbial clauses'.

Neste estudo, argumentamos que as causais de enunciação funcionam basicamente como asserções dependentes, que justificam ou explicam a causa, a razão ou o motivo que leva o falante a dizer algo, e propomos a designação de Justificação para a relação discursiva que nestas construções se atualiza. ${ }^{4}$ Utilizamos a expressão 'relação discursiva' como sinónima de relação de coerência ou da relação retórica, ou seja, uma relação de sentido que permite interligar ou conectar enunciados, dando origem a um texto.

Centremos então a nossa análise no exemplo (2). É óbvio que o facto de as luzes estarem acesas não é a causa de o Pedro estar em casa. Assim, não estamos perante uma causal prototípica, em que o nexo de causa-efeito se estabelece entre situações do mundo linguisticamente representadas. Ao utilizar o conector 'porque', comutável por 'pois', o falante explica ou justifica a asserção prévia, aduzindo evidência empírica que, em sua opinião, a sustenta. ${ }^{5}$ Neste sentido, as paráfrases mais fiéis de (2) seriam (2 a), (2b) ou (2c):

(2a) O facto de eu saber que as luzes estão acesas leva-me a concluir que o Pedro está em casa.

(2b) A causa/ a razão/ o motivo que me leva a concluir que o Pedro está em casa é o facto de as luzes estarem acesas.

(2c) Afirmo/concluo que o Pedro está em casa. E digo isto porque as luzes estão acesas.

É possível problematizar esta distinção e avançar para uma tipologia mais granulada da relação de causa. Confira, entre outros, Mann e Thompson (1988), Sweetser (1999).

4 Sobre esta linha de argumentação, veja-se Neves (1998), Lopes (2005; 2009), e também Peres e Mascarenhas (2006).

5 Assinale-se que as orações causais enunciativas (ou explicativas) e as tradicionalmente chamadas orações conclusivas funcionam em espelho. Assim, (2) equivale semanticamente a 'As luzes estão acesas, logo/ portanto, o Pedro está em casa'. 
Trata-se, pois, da explicitação da causa do dizer, e não da causa do dito. Noutros termos, a causal introduzida por 'porque' modifica o dizer e não o dito. Note-se, na paráfrase apresentada em (2c), a ocorrência do verbo declarativo 'dizer', na $1^{a}$ pessoa do singular do Presente do Indicativo, que claramente indicia uma conexão ao nível enunciativo-pragmático. ${ }^{6}$

Uma análise semântica do exemplo (2) mostra-nos que há um esquema inferencial subjacente: assumindo uma premissa genérica implícita normalmente, se/quando o Pedro está em casa, as luzes estão acesas e sabendo que as luzes estão acesas, o falante assere, concluindo o seu raciocínio, que o Pedro está em casa. Trata-se de um esquema inferencial defetivo, um entimema, uma vez que uma das premissas (a premissa genérica) não está expressa. Sublinhe-se que a proposição expressa na primeira asserção admite a paráfrase 'o Pedro deve estar em casa', uma proposição epistemicamente modalizada que traduz uma hipótese fortemente provável e sublinha o estatuto intensional da predicação.

Como já foi assinalado por Peres e Mascarenhas (2006), o produto final resultante da conexão explicativa não é uma proposição, na medida em que não pode ser avaliado em termos de valor de verdade, mas sim em termos de validade argumentativa. Veja-se a linha de raciocínio dos autores, a partir dos exemplos por eles propostos:

(3) O Pedro deve ter saído, porque não o vejo em lado nenhum.

(4) \# O que disseste é falso.

(5) O que disseste é ilógico / incongruente / não faz sentido.

Só (5) seria uma réplica adequada a (3), o que demonstra que (3) não funciona, de facto, como proposição (complexa).

Outro aspeto relevante a evidenciar, na análise deste tipo de causais de enunciação, prende-se com a dimensão ilocutória autónoma (embora interdependente) dos segmentos conectados. Com efeito, estamos perante uma sequência de atos discursivos ou ilocutórios: uma asserção inicial que configura o ato principal, e uma segunda asserção que funciona retroactivamente como justificação da primeira, realizando um ato subordinado. ${ }^{7}$ De notar o caráter hierárquico e funcional desta articulação de atos sequenciais: o locutor apresenta o conteúdo proposicional da segunda asserção como argumento para a conclusão expressa na asserção inicial.

\footnotetext{
É sabido que em línguas como o francês, o inglês ou o alemão, os falantes selecionam conectores específicos para este tipo de construções: car ou puisque, for ou since, denn, respetivamente. Em Português, os conectores que prototipicamente são selecionados são porque e pois e que (este último em contextos em que a oração matriz é uma frase imperativa).

7 Esta distinção entre atos principais e atos subordinados aparece já em Dijk (1977) e Roulet et al. (1985)
} 
Em Sweetser (1999), construções como as que (2) ilustra são chamadas causais epistémicas, uma vez que envolvem o mundo do raciocínio do falante, ancorado nos seus conhecimentos e/ou crenças. ${ }^{8}$ Em nossa opinião, em construções deste tipo, que configuram textos de natureza argumentativa na sua estrutura mais simples ou elementar, não é possível dissociar o domínio epistémico do domínio ilocutório da significação: asserir uma determinada conclusão e seguidamente explicar/justificar essa conclusão implica, sem dúvida, encadear ou desenvolver um raciocínio, mas também, de forma central, articular asserções com estatutos funcionais distintos (conclusão e premissa ou argumento a favor dessa conclusão). Assim, defendemos que um enunciado como (2) configura uma ilocução complexa composta por duas ilocuções elementares pertencentes à esfera dos atos assertivos, cada um deles com distinta função no quadro da argumentação em curso.

Consideramos, pois, que "[...] the act of concluding may be speaker-internal, but since it is asserted and then justified/explained, it is not possible to dissociate the epistemic and the illocutionary domains within he field of argumentative texts." (LOPES, 2009, p.11). Pelos motivos aduzidos, estas causais de enunciação exibem uma relação discursiva de tipo pragmático-funcional: o segundo membro da construção justifica a asserção inicial, justamente porque o seu conteúdo proposicional é apresentado como argumento válido para sustentar a conclusão inferida pelo locutor.

Note-se que a mesma relação discursiva subsiste na ausência do conector:

(2d) O Pedro está em casa. As luzes estão acesas.

Face a (2d), o interlocutor reconstrói inferencialmente o nexo de justificação que permite interligar de forma coerente os dois enunciados. A presença do conector, ao sinalizar explicitamente a relação discursiva intendida pelo falante, fornece uma pista que eventualmente diminui o esforço cognitivo ao nível do processamento. Neste sentido, podemos dizer que o conector funciona como um operador de processamento que otimiza o esforço dispendido na interpretação.

O diferente comportamento sintático das causais de enunciação, face às causais de enunciado, pode, a nosso ver, ser explicado em função do caráter pragmático-funcional da relação discursiva em apreço. Assim, se se admitir, como é assumido na teoria clássica dos atos ilocutórios (SEARLE, 1969), que o suporte linguístico de um ato é tipicamente uma frase, e se se aceitar a hipótese acima defendida de que em (2) o falante realiza dois atos ilocutórios sequencialmente

Para além das causais epistémicas, Sweetser (1999) considera também as causais de conteúdo, que poderiam ser ilustradas pelo nosso exemplo (1), e as causais ilocutórias, que expressam a causa ou o motivo de um ato discursivo. O exemplo que a autora avança para ilustrar este ultimo tipo de causais envolve uma pergunta seguida de justificação. 
interligados, então ter-se-á de concluir que o produto final resultante da conexão é um texto, mas não uma frase complexa. Os testes avançados em Peres (1997) apontam no mesmo sentido. Vejam-se os exemplos (6) e (7):9

(6) *O Rui acredita [que [o Pedro está em casa, porque as luzes estão acesas]].

(7) *Provavelmente [o Pedro está em casa, porque estão as luzes acesas].

A noção de suplementação, avançada por Huddleston e Pullum (2002) e retomada por Peres e Macarenhas (2006), poderia eventualmente ultrapassar a polémica acesa sobre o estatuto coordenado ou subordinado destas construções. Com efeito:

[...] it is the lack of integration into the syntactic structure that distinguishes supplementation from dependency constructions and coordination. But supplementation is like coordination in being nonheaded: since the supplement is not integrated in the structure it cannot function as a dependent to any head. (HUDDLESTON; PULLUM, 2002, p.1350).

E, mais adiante, os mesmos autores afirmam: "although supplements are not syntactically dependent on a head, they are semantically related to what we call their anchor." (HUDDLESTON; PULLUM, 2002, p.1351, grifo nosso). Esta "relação semântica" facilmente converge com a hipótese que temos vindo a defender: a relação discursiva de justificação articula os dois membros da construção, dando origem a um produto final que é coerente, uma dimensão central da textualidade.

Retomem-se agora, sob este novo ângulo de visão, alguns dos testes recorrentemente convocados para dar conta do comportamento diferenciado das causais de enunciação (ou explicativas) face às causais de enunciado.

Nas causais de enunciação, não é possível inverter a ordem dos membros, como se atesta em (8):10

(8) *Porque/pois estão as luzes acesas, o Pedro está em casa.

Facilmente se compreende esta resistência à anteposição, se se atender ao processo icónico de ordenação dos atos discursivos relevantes: só se pode justificar algo que foi previamente verbalizado.

9 O asterisco no exemplo (6) significa apenas que a segunda proposição não funciona como complemento do verbo 'acreditar'; o mesmo asterisco, em (7), significa apenas que no escopo do advérbio de frase se encontra apenas a primeira proposição.

10 Note-se o contraste com as subordinadas causais prototípicas: (i) Porque choveu, as ruas estão molhadas. 
Por outro lado, as causais de enunciação rejeitam a focalização por clivagem (9) e não ocorrem no escopo da negação de foco (10):

(9) *É porque/pois as luzes estão acesas que o Pedro está em casa.

(10) *O Pedro não está em casa, porque/pois as luzes estão acesas. ${ }^{11}$

A nosso ver, é ainda o caráter ilocutoriamente autónomo do segundo membro da construção que determina a resistência das causais de enunciação aos testes acima aplicados. Com efeito, só podem ser focalizados constituintes sintáticos de uma frase matriz que, ao ser enunciada, corresponde à realização de um só ato discursivo. Ora, não sendo o produto final resultante da conexão de uma frase complexa, mas sim de um texto, a proposição introduzida pelo conector 'porque' ou 'pois', nas causais de enunciação, não pode ser considerada um constituinte sintático de uma frase matriz inexistente.

Note-se, no entanto, que a focalização por clivagem seria possível se fosse explicitado o verbo declarativo no segundo membro da construção, como se demonstra em (11):

(11) É porque as luzes estão acesas que eu digo que o Pedro está em casa.

Outro comportamento sintático relevante das causais de enunciação prendese com a possibilidade de ocorrerem facilmente depois de uma interrogativa-tag. Veja-se (12): ${ }^{12}$

(12) O Pedro está em casa, não está?, porque as luzes estão acesas.

Relembrando que as interrogativas-tag seguem tipicamente uma frase declarativa, suporte típico de uma asserção, facilmente se explica a plena aceitabilidade de (12): o falante, através da interrogativa-tag, pretende que o interlocutor confirme a conclusão asserida, e aduz seguidamente o argumento que a justifica.

Outra propriedade das causais de enunciação é o facto de não poderem ser substituídas por causais infinitivas introduzidas por 'por', como se atesta em (13):

*O Pedro está em casa por as luzes estarem acesas. ${ }^{13}$

\footnotetext{
11 O asterisco significa que no escopo da negação está apenas a primeira proposição expressa.

12 Contraste-se com (i): *As ruas estão molhadas, não estão? porque choveu.

13 Contraste-se com (i) O Pedro está doente por ter comido muito chocolate.
} 
Já em Lobo (2003), Lopes (2004) e Lopes (2005) se aponta para o facto de o conector 'por', seguido de oração infinitiva, introduzir sempre uma causal integrada, que funciona ao nível do domínio do conteúdo, explicitando a causa propriamente dita da situação descrita na oração principal. Por outras palavras, numa construção do tipo 'p por + oração infinitiva', o locutor assere a relação causal, realizando um único ato ilocutório; daí a impossibilidade de ocorrência do conector 'por' nas causais de enunciação, que envolvem uma articulação sequencial de dois atos ilocutórios. Finalmente, refira-se a pausa obrigatória que separa a causal de enunciação da asserção prévia, marcada na escrita por vírgula. Características prosódicas sinalizam a não integração sintática da causal de enunciação, que, por seu turno, reflete, na nossa opinião, a sua forte autonomia ilocutória.

Atente-se agora nos conectores 'visto que', 'dado que', 'uma vez que' e 'já que', de modo a testar se podem ou não introduzir causais de enunciação em Português. Em Lopes (1971, p.27), encontra-se já um exemplo em que 'visto que' introduz a razão pela qual o locutor conclui algo. O exemplo é o seguinte:

(14) "Teve um desgosto, porque (visto que; pois) chorou."

No corpus CETEM Público, foram encontrados vários exemplos de causais de enunciação introduzidas por 'já que', 'uma vez que', 'dado que' e 'visto que'. Destacam-se os seguintes:

(15) "A saída para este caso não será pacífica, já que nem todos os dirigentes do executivo partilham da mesma ideia".

(16) "O valor apresentado pela comissão parece situar-se num nível de consenso [...], uma vez que foi bem aceite por sindicatos e associações patronais."

(17) "As baterias [...] deverão ter sobrevivido intactas, visto que [...] tinham sido concebidas para suportar a entrada na atmosfera marciana [...]"

(18) "A ameaça dos trabalhadores portuários de pararem os portos nacionais amanhã não deverá surtir efeito, dado que o pagamento da indemnização começa a ser feito esta semana."

Todos estes exemplos ativam uma leitura explicativa similar à que foi explicitada na análise do exemplo (2): o falante assere uma conclusão e justifica seguidamente a sua asserção convocando um argumento que a sustenta e que se articula com uma premissa genérica implícita. É sempre possível recuperar, na paráfrase de cada um dos exemplos acima elencados, um verbo declarativo na $1^{\mathrm{a}}$ pessoa do singular ( $\mathrm{p}$, e digo isto porque $\mathrm{q}$ ). 
Parece-nos de crucial relevância assinalar que o primeiro membro da construção, nestes exemplos extraídos do CETEM Público, envolve sempre um marcador de modalização. Assim, em (15), observamos um uso modal do Futuro do Indicativo; em (16) ocorre o verbo 'parecer', que inscreve no enunciado um valor modal epistémico de não certeza, compatível com a expressão de uma conclusão do falante inferida a partir do argumento apresentado e de uma premissa implícita que configura conhecimento do mundo compartilhado; em (17) e (18), o verbo modal dever inscreve, no primeiro membro do enunciado, um valor modal epistémico de probabilidade, corroborado ou intensificado pela ocorrência do Futuro do Indicativo com interpretação modal.

Os dados empíricos confirmam, portanto, o que acima se disse a propósito do exemplo (2), um exemplo construído sem marcas explícitas de modalização: nas construções que envolvem causais de enunciação, a predicação que configura a conclusão asserida pelo falante tem sempre uma interpretação intensional. De facto, não poderia ser de outro modo: tais predicações descrevem o resultado de um raciocínio, de uma inferência realizada pelo falante. ${ }^{14}$ Note-se o imediato bloqueio de uma leitura de causal enunciativa em enunciados como o que se segue, em que o primeiro membro da construção é extensionalmente interpretado, dado que descreve um evento factual:

(19) \# O ministro reafirmou em conferência de imprensa os cortes salariais, porque/pois o déficit assim o exige.

Nos corpora utilizados, a causal de enunciação introduzida pelos conectores 'visto que', 'dado que', 'uma vez que' e 'já que' encontra-se tipicamente posposta à asserção que configura a conclusão inferida pelo falante.

Importa agora qual o estatuto do segundo membro das causais de enunciação em termos de informatividade. Tratando-se de um argumento invocado para justificar o dito, é sempre, necessariamente, informação tida como conhecida ou tomada como dado adquirido pelo falante. As causais de enunciação têm, pois, um caráter inerentemente pressuposicional, ${ }^{15} \mathrm{o}$ que se conjuga plenamente com o facto de serem incompatíveis com processos de focalização: de facto, só informação apresentada como não conhecida ou não pressuposta pode ser focalizada. Assim, mesmo quando as causais de enunciação são introduzidas por conectores como 'porque' ou 'pois', que, contrariamente aos conectores 'visto que', 'dado que', uma vez que', 'já que', não estão marcados positivamente no Léxico por um traço semântico-

14 A expressão "subject of consciousness" é utilizada por Maat e Sanders (2000) para dar conta do envolvimento do falante nas construções que não expressam relações objetivas (de causa-consequência) de entre situações do mundo, embora recorram a conectores com valor causal.

15 Por 'pressuposição' entende-se aqui informação assumida pelo falante como dado adquirido. 
discursivo [+pressuposicional], ${ }^{16}$ o conteúdo proposicional de uma causal de enunciação, pelas razões semântico-pragmáticas acima aduzidas, terá sempre um estatuto de informação conhecida.

Até aqui, foram analisadas construções que articulam uma causal de enunciação com uma frase declarativa, suporte típico da asserção. No parágrafo que se segue, focaliza-se a articulação de causais de enunciação com frases imperativas e interrogativas.

\section{Causais de enunciação articuladas com atos diretivos ${ }^{17}$}

Veja-se agora um exemplo distinto dos anteriores, mas em que ocorre igualmente uma causal de enunciação:

(20) Levanta-te, que/porque/pois são horas de ir para a escola!

Em contextos deste tipo, isto é, em contextos em que o primeiro membro da construção é uma frase imperativa, suporte típico de realização de um ato diretivo com diversos graus de impositividade, é corrente, no Português europeu contemporâneo, o uso do conector 'que' (comutável por 'porque' e 'pois'). Só as causais de enunciação admitem, como primeiro membro, uma frase imperativa. Tal facto é perfeitamente compaginável com o enquadramento descritivo-explicativo que temos vindo a desenvolver: se a causal de enunciação estabelece com o primeiro membro da construção uma relação discursiva de justificação, nada impede que ela possa coocorrer com um enunciado com uma força ilocutória distinta da assertiva. Com efeito, é totalmente plausível justificar um ato ilocutório diretivo impositivo (ordem ou proibição). Mais ainda: do ponto de vista da interação verbal, a justificação de um ato diretivo impositivo, intrinsecamente ameaçador da face do outro, pode inclusivamente potenciar a eficácia perlocutória desse ato. Efetivamente, a explicitação do motivo que está na origem de uma injunção parece configurar uma estratégia discursiva de atenuação da relação de poder e controle do locutor sobre o interlocutor, tendente à eventual mitigação de uma atitude de resistência por parte deste último.

Note-se, uma vez mais, que a mesma relação discursiva seria computada na ausência do conector:

(20a) Levanta-te! São horas de ires para a escola.

16 Assume-se, na esteira de Lobo (2003), que os conectores 'visto que', 'dado que', uma vez que', 'já que' têm no Léxico o traço semântico-discursivo [+pressuposicional].

17 De acordo com a tipologia de Searle (1969), incluímos nos atos diretivos as ordens, os pedidos, os conselhos e as perguntas. 
Veja-se ainda um outro exemplo em que o primeiro membro da construção é uma frase imperativa que realiza, desta feita, um ato diretivo não impositivo, um conselho ou uma recomendação:

(21) Acaba a tese, que/porque é a única maneira de teres o contrato renovado!

Neste último exemplo, o locutor justifica o conselho formulado aduzindo um argumento que sublinha as consequências positivas que o seu acatamento acarretará para o interlocutor..$^{18}$ Assim, o falante, ao formular um ato subordinado de justificação, ativa uma estratégia discursiva que tende a potenciar o efeito intendido do seu ato ilocutório principal: levar o outro a aderir ao conselho, pondo-o em prática.

Tanto em (20) como em (21), a causal de enunciação não pode ser anteposta à frase imperativa. No entanto, se as causais de enunciação forem introduzidas pelos conectores 'já que', 'uma vez que', 'dado que' e 'visto que', a anteposição torna-se possível, como se atesta em (22):

(22) Já que/ uma vez que/dado que/visto que vais sair, compra pão.

Neste caso, a causal, não deixando de justificar o pedido, parece estar igualmente ao serviço de uma estratégia discursiva de reforço, ao fazer referência ao facto, dado como adquirido, de que estão reunidas as condições necessárias para que esse pedido seja cumprido.

Atente-se agora na compatibilidade entre causais de enunciação e perguntas, a partir do exemplo (23):

(23) Tens planos para logo à noite? Porque gostava de te convidar para irmos ao cinema. ${ }^{19}$

Em (23), o primeiro membro da construção é uma pergunta que funciona como ato diretor ou principal, e o segundo membro funciona como ato subordinado de justificação. No Português europeu contemporâneo, a construção mais produtiva para a realização de um complexo ilocutório deste tipo seria, sem dúvida, (23a):

(23a) Tens planos para logo à noite? É que queria convidar-te para irmos ao cinema.

De qualquer modo, tanto (23) como (23a) admitem a mesma paráfrase:

18 Parece haver aqui subjacente um esquema pragmático de argumentação, ancorado na assunção de que se deve optar pela forma de comportamento que nos traz consequências positivas.

19 Exemplo inspirado em Sweetser (1999). 
(23b) Tens planos para logo à noite? Faço esta pergunta/pergunto-te isto porque queria convidar-te para irmos ao cinema.

Esta paráfrase mostra claramente que estamos perante a expressão da causa ou da razão que explica o ato ilocutório de pergunta realizado no primeiro enunciado. A construção com 'é que', em (23a), pode ser analisada como uma construção clivada em que o constituinte posto em destaque, ou focalizado, tem de ser cotextualmente inferido. ${ }^{20}$ Concretizando: o SN anaforicamente inferível, em (23a), seria 'a causa/razão da pergunta [anteriormente formulada]'. Mas o que importa realçar é o facto de a mesma relação discursiva pragmático-funcional de justificação poder ser igualmente processada em contextos em que o que se justifica é um ato ilocutório diretivo de pergunta.

Mais uma vez se chama a atenção para o facto de a mesma relação discursiva de justificação poder prescindir em absoluto de conectores:

(23c) Tens planos para hoje à noite? Queria convidar-te para irmos ao cinema.

No CdP, foram encontrados vários exemplos de causais de enunciação introduzidas pelo conector 'visto que' (comutável por 'dado que', 'uma vez que', já que') e articuladas com frases interrogativas. Selecciou-se o que se segue, pelo seu caráter paradigmático:

(24) "Que fico aqui a fazer, visto que a minha presença na loja não é imprescindível?"

Confrontado (24) com (23), há um aspeto que chama desde logo a nossa atenção: em (24), a razão invocada para a justificação da pergunta é apresentada como pressuposta, dado o traço [+pressuposicional] associado lexicalmente ao conector, o que não acontece com a razão invocada em (23a). Neste tipo de contextos - pergunta + justificação da pergunta -, os dados parecem apontar para o seguinte padrão: quando a razão invocada para explicar a pergunta é tida como conhecida, o locutor seleciona o subconjunto dos conectores causais marcados com o traço [+pressuposicional]. Nos restantes casos, no Português europeu, o molde prototípico é o que envolve a construção 'p? É que q'.

20 Para o estudo desta estrutura, veja-se, e.o., Declerk (1992) e Delahunty (1995). 


\section{Causais de enunciação e outras classes de atos ilocutórios}

Atente-se, finalmente, nos exemplos (25) e (26), que envolvem a articulação de uma causal de enunciação com enunciados que realizam, respetivamente, um ato ilocutório compromissivo e um ato ilocutório expressivo:

(25) Prometo visitar-te, porque/pois sei que precisas de desabafar.

(26) Lamento que tenhas reprovado, porque/pois sou testemunha de te esforçaste.

As paráfrases (25a) e (26a) provam que se trata de facto de causais enunciativas:

(25a) Prometo visitar-te, e faço esta promessa porque sei que precisas de desabafar.

(26a) Lamento que tenhas reprovado, e lamento porque sou testemunha de que te esforçaste.

Também nestes casos a relação discursiva de justificação seria processada mesmo na ausência de conectores:

(25a) Prometo visitar-te. Sei que precisas de desabafar.

O conector 'que' parece excluído deste tipo de construções, mas os conectores 'dado que', visto que', 'uma vez que' e 'já que' são perfeitamente aceitáveis:

(25b) */?? Prometo visitar-te, que sei que precisas de desabafar.

(26b) *Lamento que tenhas reprovado, que sou testemunha de que te esforças.

(25c) Prometo visitar-te, visto que/dado que/uma vez que/já que sei que precisas de desabafar.

(26c) Lamento que tenhas reprovado, visto que/dado que/uma vez que/já que sou testemunha de que te esforçaste.

O facto de os conectores 'porque' ou 'pois' serem comutáveis pelos conectores causais com o traço [+pressuposicional] parece apontar para uma restrição pragmática: a razão invocada pelo falante que realiza um ato principal expressivo tem o estatuto de informação assumida como dado adquirido. Isto mesmo quando não ocorrem predicadores epistémicos (como saber, ser testemunha) na causal, como se ilustra em (27) e (28):

(27) É condenável a tua atitude, porque/pois/visto que sempre foste bem acolhida pela instituição. 
(28) Deploro a tua reação, porque/pois/ visto que ultrapassaste todos os limites da boa educação.

\section{Considerações finais}

Em todos os exemplos analisados neste artigo (exceto o exemplo (1)) se verifica o mesmo denominador comum: a causal justifica o dizer e não o dito, sendo que esse dizer pode ser uma asserção, um ato diretivo, um ato compromissivo ou um ato expressivo.

O que diferencia o exemplo (1) de todos os outros é o facto de o primeiro convocar, de forma intrinsecamente indissociável, os domínios epistémico e ilocutório da significação: o falante verbaliza um raciocínio, articulando duas asserções funcionalmente distintas (uma delas assume a função de conclusão e configura o ato discursivo principal, a outra funciona retroactivamente como ato subordinado de justificação, através do qual o falante joga um determinado conteúdo proposicional como argumento para a conclusão).

A justificação de um ato de fala distinto da asserção não convoca o raciocínio do falante. Por outras palavras, quando o que se justifica não é uma asserção, mas um ato diretivo, compromissivo ou expressivo, o domínio ilocutório da significação parece ser o domínio efetivamente relevante em termos de caracterização da relação discursiva em apreço.

Neste sentido, parece legítimo estabelecer uma distinção entre, por lado, causais de enunciação que justificam uma asserção inferida (exemplo (2)) e, por outro, causais de enunciação que justificam atos ilocutórios não assertivos (exemplos (20), (23), (25), (26)). De qualquer modo, o que importa salientar é que se trata sempre de uma mesma relação discursiva: a relação de Justificação. Assim, concluímos defendendo que as causais de enunciação ilustram uma relação sequencial entre atos discursivos, funcionando sempre como atos subordinados relativamente a atos principais. Trata-se claramente de uma relação discursiva pragmático-funcional, já que opera ao nível da articulação de atos discursivos.

O plano de significação em que operam as causais de enunciação parece ser um elemento essencial para a explicação do seu comportamento sintático periférico. Com efeito, tal comportamento sintático periférico relativamente à predicação com que se articulam pode ser perspetivado como resultado da autonomia ilocutória dos dois membros da construção. Por outro lado, a hipótese defendida neste artigo ilumina também as características prosódicas das causais de enunciação. Assim, uma caracterização semântico-pragmática parece fornecer a chave para outros níveis de análise, apontando para uma interface produtiva entre gramática e discurso. 


\section{Agradecimentos}

Agradeço os comentários feitos pelos revisores anônimos à primeira versão deste trabalho.

LOPES A. C. M. Utterance causal clauses in contemporary European Portuguese: some contributions. Alfa, São Paulo, v.56, n.2, p.451-468, 2012.

- ABSTRACT:The main purpose of this paper is to characterize utterance causal clauses within a theoretical framework that assumes different domains of discourse meaning - content, epistemic and speech-act domain. The assumption is that a semantic analysis may provide some explanation for the syntactic behaviour of the construction under scrutiny. It is argued in this paper that utterance causal clauses illustrate the discourse relation of Justification, which involves the connection between two illocutionary acts, with different hierarchical status. It is also argued, contrary to Sweetser's 1999 account, that utterance causal clauses combined with assertions give rise to an elementary argumentative text, where the epistemic and the illocutionary domain are closely intertwined. The paper also contemplates the connection between utterance causal clauses and other classes of speech acts, namely directive, compromissive and expressive ones.

- KEYWORDS:Utterance causal clauses. Peripheral subordinate clauses. Speech-act. Discourse relation.

\section{REFERÊNCIAS}

BOSQUE, I.; DEMONTE, V. (Org.). Gramática descriptiva de la lengua Española. Madrid: Espasa Calpe, 1999. 3v.

DECLERK, R. The inferential it is that- construction. Lingua, Amsterdam, v.87, p.203-230, 1992.

DELAHUNTY, G. The inferential constructions. Pragmatics, San Diego, v.5, p.341364, 1995.

DIJK, T. A. V. Studies in the pragmatics of discourse. The Hague: Mouton de Gruyter, 1977.

HALLIDAY, M. A. K. Explorations in the functions of language. London: Edward Arnold, 1973.

HENGEVELD, K. Adverbial clauses in the languages of Europe. In:VANAUWERA, J. (Ed.). Adverbial constructions in the languages of Europe. Berlin: Mouton de Gruyter, 1993. p.335-419.

HUDDLESTON, R. D.; PULLUM, K. The Cambridge grammar of the English language. Cambridge: CUP, 2002. 
KORTMANN, B. Adverbial subordination: a typology and history of adverbial subordinators based ob European languages. Berlin/NewYork: Mouton de Gruyter, 1996.

LOBO, M. F. H. S. Aspetos da sintaxe das orações subordinadas adverbiais. 2003. 452f. Tese (Doutorado em Linguística) - Faculdade de Ciências Sociais e Humanas, Universidade Nova de Lisboa, Lisboa, 2003.

LOPES, A. C. M. Justification: a coherence relation. PragmaticS, San Diego, v.19, n.2, p.223-239, 2009.

. Texto e coerência. Revista Portuguesa de Humanidades, Braga, v. 9, n.1/2, p.13-33, 2005.

LOPES, H. C. Aspetos sintáticos, semânticos e pragmáticos das construções causais: contributo para uma reflexão sobre o ensino da gramática. 2004. $392 f$. Tese (Doutorado em Linguística) - Universidade do Porto, Porto, 2004.

LOPES, O. Gramática simbólica do Português. Lisboa: Calouste Gulbenkian, 1971.

LYONS, J. Semantics. Cambridge: CUP, 1977. v.2.

MAAT, P.; SANDERS, T. Domains of use or subjectivity? The distribution of three Dutch causal connectives explained. In: COUPER-KULHEN, E.; KORTMANN, B. (Ed.). Cause, condition, concession and contrast: cognitive and discourse perspetives. Berlin: Mouton de Gruyter, 2000. p.57-82.

MANN, W. C.; THOMPSON, S. A. Rhetorical structure theory: a theory of text organization. Text, Berlin, v.8, p.243-281, 1988.

MATOS, G. Coordenação frásica vs. subordinação adverbial. In: ENCONTRO NACIONAL DA ASSOCIAÇÃO PORTUGUESA DE LINGUÍSTICA, 19., Lisboa. Atas... Lisboa: Colibri, 2004. p.555-567.

NEVES, M. H. M. Uma versão integrada das construções complexas de causalidade. In: ENCONTRO DA ASSOCIAÇÃO PORTUGUESA DE LINGUÍSTICA, 13., Lisboa. Atas... Lisboa: Colibri, 1998, p.143-154.

PERES, J. Sobre conexões proposicionais em Português. In: BRITO, A. M. et al. (Org.). Sentido que a vida faz: estudos para Óscar Lopes. Porto: Campo das Letras, 1997. p.775-787.

PERES, J.; MASCARENHAS, S. Notes on sentential connections (predominantly). Journal of Portuguese Linguistics, Lisboa, v.5, n.1, p.113-167, 2006.

QUIRK, R. et al. A comprehensive grammar of the English language. London: Longman, 1985. 
RENZI, L.; SALVI, G.; CARDINALETTI, A. (Org.). Grande grammatica Italiana di consultazione. Bolonha: Il Mulino, 2001. 3v.

ROULET, E. et al. L'articulation du discours en français contemporain. Berne: Peter Lang, 1985.

SANDERS, T. et al. Toward a taxonomy of coherence relations. Discourse Processes, Norwood, v.15, p.1-35, 1992.

SEARLE, J. Speech acts. Cambridge: Cambridge University Press, 1969.

SWEETSER, E. From etymology to pragmatics. Cambridge: Cambridge University Press, 1999.

Recebido em 18 de abril de 2011.

Aprovado em 20 de agosto de 2012. 